This item was submitted to Loughborough's Research Repository by the author.

Items in Figshare are protected by copyright, with all rights reserved, unless otherwise indicated.

\title{
Aligning the times: Exploring the convergence of researchers, policy makers and research evidence in higher education policy making
}

PLEASE CITE THE PUBLISHED VERSION

https://doi.org/10.1177/0034523720920677

PUBLISHER

Sage

VERSION

VoR (Version of Record)

PUBLISHER STATEMENT

This is an Open Access Article. It is published by Sage under the Creative Commons Attribution 4.0 Unported Licence (CC BY). Full details of this licence are available at: http://creativecommons.org/licenses/by/4.0/

LICENCE

CC BY 4.0

\section{REPOSITORY RECORD}

Smith, Karen, Scott Fernie, and Nick Pilcher. 2020. "Aligning the Times: Exploring the Convergence of Researchers, Policy Makers and Research Evidence in Higher Education Policy Making”. Loughborough University. https://hdl.handle.net/2134/13720696.v1. 


\title{
Aligning the times: Exploring the convergence of researchers, policy makers and research evidence in higher education policy making
}

Research in Education 202I, Vol. IIO(I) 38-57 (C) The Author(s) 2020

(c) (i)

Article reuse guidelines: sagepub.com/journals-permissions DOI: I 0.II77/0034523720920677

journals.sagepub.com/home/rie

\section{Karen Smith}

School of Education, University of Hertfordshire, UK

\section{Scott Fernie}

School of Architecture, Building and Civil Engineering, Loughborough University, UK

\section{Nick Pilcher $(\mathbb{D}$}

The Business School, Edinburgh Napier University, UK

\begin{abstract}
The complexity of contemporary higher education policy making and the multitude of evidences and actors in policy networks mean that relationships between higher education researchers, policy makers and research evidence are not straightforward. In this article, we use a theoretical lens of time, Adams' Timescapes, to explore this relationship and better understand why the research and policy worlds are frequently described as divided. Drawing on in-depth interviews with higher education researchers, policy makers and research funders, we show how research and policy have different interpretations of time. We discuss the Timeframes, or lengths, of work
\end{abstract}

\section{Corresponding author:}


and career, the Temporality, or complexity, of 'evidence', of networks and relationships, and the importance of elements such as Timing, or synchronisation, and Tempo, or pace. We conclude that policy makers and higher education researchers may be better able to make sense of the problematic nature of aligning their concerns, interests and actions through understanding different Timescapes.

\section{Keywords}

Evidence-informed policy, higher education, policy making, research-policy nexus, time

\section{Introduction}

In this paper, we explore the extent to which the convergence of researchers, policy makers and research evidence in higher education policy making can be better understood when viewed through the theoretical lens of time. Time is key to interactions within and between the very different practical and institutional landscapes of research and policy (Broadbent, 2017). It is also extremely influential in how evidence is used (Oliver et al., 2014b) both by politicians (e.g. Coffé, 2017) and also in policy construction (Strassheim, 2016). Exploring time in the researchpolicy nexus can thus provide clearer explanations of evidence-based policy and why policy makers are argued to 'interact with research too late or, largely ignore research in favour of the quick-fix bright ideas of spin-doctors and advisers' (Lawton, 2005: 142). Time has also featured heavily in arguments made concerning the problems of supply and demand of evidence in policy making (Rutter, 2012). In this introduction, we consider the key issues of evidence and policy making, the type of evidence policy makers want, higher education policy networks, and the role of time in policy making. We then end the introduction by outlining our approach to the study and detailing the remainder of the article.

\section{Evidence and policy making}

Evidence is mobilised in various ways to underpin the development of public and social policy (Brown, 2013). It can provide rigor, reliability, relevance and legitimacy to the development and diffusion of policy and act as the basis for building coalitions or networks of influence (Béland and Cox, 2016) to shape policies. Exploring whose evidence is used (or not), how, why and when in policy making provides an opportunity to gain insights into the policy making process. This is particularly important given that policy making is no longer viewed as simply a rational-technical process where evidence drawn upon dominates what is 'made', but rather as an interpretative process whereby policy makers continually incorporate a range of new information alongside other factors in making intuitive decisions (Brown, 2014). Here, the emphasis is on meaning making between policy network actors who use and interpret evidence (Pearce et al., 2014) and 
where the dynamics between those actors are unstable (Ball and Exley, 2010), not least through time. Critically, time and policy are very closely intertwined, and the ways in which time is conceptualised 'are closely related to underlying understandings of politics and political action' (Strassheim, 2016: 151). Moreover, how time is viewed is extremely influential to what can be achieved in policy, how quickly, how much time is required to achieve it, whether there is a lack of time, whether a policy is considered timely or whether it is considered to be of a nature that is timeless. It is clear that 'theories of time are not only political theories but also a form of political practice' (Strassheim, 2016: 151).

Multiple frameworks have been used (see e.g. Weible and Sabatie, 2017) to help explain the inherent and emergent complexities involved in contemporary policy making, otherwise described as 'wicked problems' (Ferlie et al., 2011) or a 'complex stew' (Lomas, 2000). It is necessary that these frameworks also address how power dynamics (Young et al., 2016) within and between these disparate networks are played out as they attempt to release the evidence behind the final policy. As such, interests, motivations and incentives to act (or not) within and across these networks cannot be assumed to easily align or integrate. Nor can they be assumed to remain static over time. While operating within this socially complex and arguably multilevel arena of policy negotiation, actors often attempt to draw upon rigorous evidence in bounded rational ways to underpin arguments, positions, assumptions and decisions. These decisions are made in particular spaces and at particular times.

Explaining evidence-based education policy making therefore necessitates an understanding of both policy networks and the type(s) of evidence sought and mobilised. However, the very definition of 'evidence' itself is problematic, and there can be a multitude of evidences (Sumner et al., 2011). Indeed, what constitutes evidence and its use involves multiple debates around a number of factors. It can involve debates around facilitators and barriers to knowledge transfer (Van de Goor et al., 2017); to the idea of objective evidence (Cairney et al., 2016) or emphasis on quantitative survey data (Boehm et al., 2013); and also to bias in the production and use of evidence (Cairney et al., 2016; Lawrence et al., 2017). Debates can also ensue as a result of disparate perspectives on utility and applicability of evidence (Dunn and Laing, 2017); individuals' values' influence on extent and use of evidence (Van de Goor et al., 2017), and who controls the selection of evidence (Flitcroft et al., 2011). Also, even the framing of evidence (Cairney et al., 2016) and the importance placed on contexts in mobilising evidence to where the action is (Cairney and Oliver, 2017) can create debate. The use of evidence is clearly not objective, or as Wesselink et al. (2014: 341) note, 'evidence cannot speak; it has to be introduced in some way by the participants as part of their framing of the policy problem'. Crucially, the nature of what evidence is considered feasible for policy must arguably fit how policy makers conceive of time (Strassheim, 2016) and how they work with the 'horizons of expectations' (Koselleck, 1979, cited in Strassheim, 2016: 154) of what can be achieved in terms of evidence in the specific Timeframes of the policy world. 


\section{The type of evidence policy makers want}

In this context, it is key to note that not all evidence is research, however, and not all research is academic (Oliver et al., 2014a), nor is all research evidence powerful enough for policy making (Whitty and Wisby, 2016). Indeed, researchers are not, as Lomas (2000: 141) points out, 'busy filling shelves of a shop-front with a comprehensive set of all possible relevant studies that a decision-maker might some day drop by to purchase'. Different types of research evidence are underpinned by specific epistemologies and methods that policy actors may interpret as having more or less legitimacy. Research evidence is not always coherent, self-evident, uncontested (Brooy and Kelaher, 2017) or, as we will argue, timely. If and when research evidence is available arguably precedes the questions of how and what. However, even if research is commissioned by policy actors after the problem has been defined, this process is subject to 'filtering' by those actors. The commissioning of research is also pragmatically delineated by the time required to provide the types of evidence and the time available to develop the policy. That the 'right' research evidence is available, commissioned in time and interpreted similarly by policy makers for solving agreed and well-defined problems at the specific points in time they emerge could simply be serendipitous or limited to windows of opportunity in time (Dunn and Laing, 2017). In a policy network then, actors will select and use specific research evidence for particular arguments and purposes at particular times.

\section{Higher education policy networks}

Higher education policy networks include various academics such as sector representatives (e.g. vice chancellors and other leaders), knowledge experts of broad policy agendas or applied policy development and diffusion (see Cairney, 2015) who are actively engaged in 'research-informed policy' (Whitty and Wisby, 2016). They also include those acting in a consultancy capacity, or others who have developed relationships with decision makers (Oliver et al., 2014b). Finally, they include those that either sit within or have critical distance from broad or specific policy arenas for the purpose of executing or commissioning policy evaluation. The network may also include representatives from parliament, government, civil services, professional bodies, industry bodies, think tanks, experts and the public. These actors draw upon freely available academic research outputs, engage with specific researchers and research institutes with particular higher education profiles and reputations or commission researchers to provide the required research or consultancy based evidence. Actors' actions designed to achieve something feasible both play out within and are also limited by a context that includes sensitivity to time and space. Academic researchers for their part play many roles in a policy network, including: 'policy intellectual' (Ball and Exley 2010), 'policy entrepreneur' (Ball, 2016; Béland and Cox 2016), 'knowledge producer' (Brooy and Kehaler, 2017) and bridge between academia and government, or 'boundary spanner' 
(Ferlie et al., 2011). Concurrently, 'public intellectual' roles exist, whereby research influences public opinion and, indirectly, policy (Kovacs, 2008; MacDonald, 2013). In all of these academic researcher roles, it is similarly necessary to be sensitive to how time both facilitates and limits what can, is or could be done in space. Significant actual and potential interactions in spaces between the parallel universes (Brownson et al., 2006) or the great cultural divide (Gornitzka, 2013) between research and policy may be considered to exist, but is arguably mediated by and through time. Even new actors (think tanks/bloggers) acting directly or opportunistically as intermediaries (Lingard, 2013; Sebba, 2011) or 'knowledge brokers' (Cairney et al., 2016) in an attempt to bridge this cultural divide are inevitably constrained or guided by time in these different worlds and spaces.

\section{The role of time in policy making}

Time has been noted to be less well established as a way to explore politics and policy making (Howlett and Goetz, 2014) and also argued to have been marginalised by space as the neglected dimension (see Dussauge-Laguna, 2012) in studies of cross national policy transfer. More recently, and arguably responding to calls for greater attention to time, studies have attempted to understand a number of elements related to time; for example, the temporal consequences of policy design choices (Taeihagh, 2017), or how an understanding of administrative and political actors' time horizons can be used to strategically manipulate a policy outcome (Hartlapp, 2017). This paper further develops studying the role of time, by considering it as something that can explain how researchers interact with (or not) higher education policy makers. We argue this is pivotal in exploring and explaining the cultural divide and the opportunities and limitations on how research (and evidence by extension) can impact on policy.

\section{Approach to the study}

Social analysis has increasingly drawn on considerations of time and its multidimensional, multifaceted and complex influence on contemporary life (Adam, 1995, 1998, 2008). Here we used Adam's (1998, 2008) Timescapes perspective. Adam's Timescapes place emphasis not on a single time, but instead on the multitude of times that may be the result of how we are expected to perform different tasks for different audiences and demands, and which interpenetrate and permeate our daily lives. Specifically, we use this Timescapes perspective as a lens to analyse the convergence and interactions between research and policy. Adam's Timescapes have been used as a lens to explore a number of areas such as distance learners' motivations for learning (Raddon, 2007), young people's financial lives (Riach et al., 2017: 206), sustainable consumption (Reisch, 2001) and to consider policy (Strassheim, 2016). In this article, we use the Timescapes to focus specifically on higher education researchers and higher education policy making. We do so both due to the paucity of research in this area (in contrast to educational research more 
broadly) and also to the charge that higher education researchers have failed to address policymakers' criticisms, resulting in a higher education policy 'researchfree' zone (Locke, 2009). Our analysis draws on in-depth interviews with UK policy actors we categorised as: higher education researchers $(n=12)$, higher education policy makers and influencers $(n=8)$ and; funders of higher education research $(n=6)$. We recognise, however, that the boundaries between these groups were blurred, with individuals inhabiting more than one role over their careers (cf. Lingard, 2013) and sometimes speaking from different perspectives; as a higher education policy maker and influencer we spoke to commented: 'we commission research ... to help us influence and shape policy... as well I used to work in [a policy making role] so I can kind of see things from different perspectives ... I also used to be a different lobbyer'.

Mechanically then, the story told to this point provides the illusion that we set up time as a lens, but the reality is that the aspect of time emerged through our initial data analysis. This triggered a second literature review and search for a lens to help us explore and explain the emergence of time and its ability to shed light on the research-policy nexus. Our analysis was in this way diffractive (Mazzei, 2014); we took new theory to revisit previously collected data and 'plugged-in' (cf. Deleuze and Guattari, 1988) this theory to the data to read it afresh for new insights and angles.

In the remainder of our article, we first provide detail about Adam's Timescapes as a theoretical lens and how we used it to analyse our data before turning to present and discuss our findings. Specifically, we focus on how the use of such a lens can help understand the nexus between research and policy making in higher education, and, ultimately, the convergence of these 'parallel universes' (Brownson et al., 2006).

\section{Time and 'Timescapes' as a theoretical lens}

Time is becoming an increasingly useful lens through which to view research data. It has been used to view the development of the European Union (Goetz and Meyer-Sahling, 2009), examine professional practices and pedagogy (Hopwood, 2014), and explore individuals' development of different future-focused selves (Dunkel and Anthis, 2001; Markus and Nurius, 1986). In cultural and intercultural studies, time is argued to be perceived differently according to culture; both as monochromic or polychronic (Hall, 2012), and as sequential or synchronous (Hampden-Turner and Trompenaars, 2002).

Within Western education, time has been considered as being unitised, with people's lives ruled by time's quantitative measurement: 'bells, timetables, schedules and educational calendars, the key structuring devices of educational practice based on clock time, are hegemonic to a point of making invisible any times constituted outside the quantitative mode' (Adam, 1995: 65). Within higher education, time has been used to see dominant pedagogical discourses such as employability and personal development planning as being 'present future' (Adam and Groves, 2007) 
and oriented by institutions (Clegg, 2010). Here, academic and student work is seen by institutions as having future benefits, pressurising individuals to continually produce more (Clegg, 2010). Elsewhere, time has been used to view vocationalisation and employability (Clegg, 2014). Regarding research specifically, such unitisation has also been noted: 'All research is structured, paced, timed, sequenced and prioritised within the overall framework of the research design, the task at hand, and the funding' (Adam, 1995: 69). Importantly for any research undertaken, 'this means that the when, how long, how often, in what order and at what speed of research is predesigned to fit the object of investigation, the research agenda and the stipulations of the funding body' (Adam, 1995). We argue that time, as a lens, can expose and explain social phenomena historically, presently or in the future.

In order to explore those understandings more closely, we used Adam's work on Timescapes $(1995,1998,2008)$. This Timescapes perspective, given its nuanced and multidimensional view of time, enabled us to compare and contrast the views of policy makers, researchers and research funders in great depth to help explore the nexus of research and policy. Specifically, we used the concepts of: Timeframe (bounded time); Temporality (the irreversible passage of time); Timing (synchronisation); Tempo (speed, pace and intensity); Duration (extent of time); Sequence (order of time); and Temporal modalities (past, present and future time) (see Table 1).

We applied these codes to the researcher, funder and policy maker interviews, comparing and contrasting accounts of the use of research evidence in policy making. We present our findings under three broad themes: Timeframes of careers

Table I. Our use of different Timescapes.

Example as applied in this study of higher education (HE) policy

Timescapes making

Timeframe (bounded time)

Temporality (the irreversible passage of time)

Timing (synchronisation)

Tempo (speed, pace and intensity)

Duration (extent of time)

Sequence (order of time)

Temporal modalities (past, present and future time)
Bounded time of careers (long or short-term); career seasons and foci; implications for identity, credibility, progression and influence.

Passing of time in policy making: rational, linear processes or complex, unpredictable and negotiated ones.

Synchronising with policy concerns; timeliness; right place, right time; fads and fashions.

Pace of policy processes; lack of time; busyness; speed of change; responsiveness.

Time available to generate and/or locate research evidence; privileging types of evidence/researchers due to turnaround times; extent of time to influence policy.

Point of engagement in policy processes; sequencing of activity: what takes place and when, what kinds of evidence are called upon when.

Past or future-focussed work; in the moment, immediate problem-drive, solution-focussed. 
and relationships; the flow of time and the importance of timing; and the pace of policy making. Verbatim quotes from higher education researchers are marked HER, higher education policy makers HEP and higher education funders HEF. We note that for reasons of ethics, we do not relate any information regarding the job descriptions of those we spoke to, nor of any of the specific policies they spoke to us about as to do this may allow them to be identified. Yet, although this means that we are unable to see specific instances of particular policies, what it does mean is that we were able to gather and present what we consider to be very significant data about the role of time in their working lives. It is to this data that we now turn. Throughout we explicitly link the data to the different theoretical Timescapes categories outlined in Table 1 to show how they relate.

\section{Findings and discussion}

\section{The Timeframes of careers and policy making relationships}

Academic careers are considered long term, careers in the policy making arena more short term, as one funder noted, policy makers 'don't tend to think long term, whereas researchers do tend to think long term' (HEF). Higher education researchers recognised the same phenomenon: 'academics, a lot of people writing around $2005 / 6$ are still around in 2016...none of the bloody civil servants are' (HER). Within the policy making arena, it was common, indeed inevitable for career progression, that people move around; for civil servants, turnover of positions was fast with frequent departmental movement: 'they'll spend a year working on consumer affairs, then ... a year ... on higher education and then ... a year working on apprenticeships' (HEP). Furthermore, governments, and by extension, particular incentives and approaches for engaging with academics, change over time, creating instability and uncertainty around personal relationships between academic researchers and policy makers: 'I think maybe just this government ... isn't interested in listening to higher education as maybe previous governments' (HEF). Connections via such relationships are thus turbulent. Commissioned research (academic or not) may be reinterpreted (or, possibly, shelved) during such turbulence, or unpredictable Temporality with the influence of researchers and their research on policy similarly fragile. For higher education academics interested in research-informed policy, especially those who have personal relationships with decision makers, interactions mediated by such Timeframes and Temporality create significant problems in developing narratives of impact and, by extension, career progression.

Whilst academics' influence in policy making might wax and wane, the Timeframe of academics' careers were deemed more enduring, and, based on long careers of engaging in higher education research; academics were frequently called on for legitimate evidence in relation to policy: 'quite a lot of our work is done by academics or, or, or kind of groups within universities' (HEP). Yet, researchers felt there were certain points, usually later in their career, when they had more 
policy influence: 'you can ... set up your career that you spent a lot of time publishing things, built up a good reputation ... then maybe at the end of your career you would have more policy influence.' With seniority comes more experience or legitimacy and a more strategic engagement in the policy making process: 'I would say that, that being a bit more experienced now I am a bit more strategic in thinking about...the things...politicians are hot on at the moment' (HER). This meant that 'more and more... I keep an ear to the ground as to what seems to be something ... politicians and policy makers want to talk about ... and that will often guide the research that I do' (HER). Comparably, policy makers felt longer academic careers were needed to create an influential body of research showing credibility and legitimacy to underpin impact: 'that research in itself builds on ... longer running academic research and they'll reference the kind of base of knowledge on which that kind of evidence gathering builds.' An enduring academic career, therefore, has long-term benefits for both academic researchers to build credibility and for policy makers as such credibility can underpin the legitimacy of policy. Over the Timeframe of an academic career then, credibility, a base of knowledge and expertise in higher education and resonance with policy directions and research at various points in policy development provide opportunities for disparate interaction. For example, it can help to inform policy, to provide legitimacy to policy ideas or, for policy networks to consume existing research and evidence, thereby positioning an academic as the shopkeeper. At different points in time, guided by observation and experience, the Timeframe of an enduring academic career embedded in policy networks means an academic can effectively interact as knowledge producer, policy intellectual, policy entrepreneur or indeed a form of higher education knowledge librarian. The model described here though is arguably research shaped by policy but, such research can also be described as research-informed policy in narratives for research excellence exercises.

Yet, although higher education researchers were often thought to have more impact later in their careers, one funder felt, 'the newer researchers ... [are] ... such a powerful force for change.' These newer researchers were both familiar with social media, setting up webinars and online groups and extremely enthusiastic and optimistic. This funder commented that if you met these newer researchers with an issue where, 'if you've ever thought that's a bit difficult.... you spend a couple of hours with them and you go "Yeah, we've got to do it, we will do it." The new generation of higher education researchers was critically important, and both funders and researchers felt that influential higher education researchers were due to retire: 'big names in higher education research are all retiring' (HEF) and 'there's a lot of people who are very close to retirement... and who are retiring' (HER). Thus, there is potential for newer voices in the field of influence.

Indeed, as the quotes above suggest, academic research and the provision of evidence is predicated on academics or research groups maintaining a strong Timeframe of relationships and positions in the network over time to invest in building credibility, legitimacy and careers. However, this may come at a cost of reinforcing arguments of the prevalence of incremental over radical change, as one 
policy maker noted: 'you don't want massive swings in higher education policy from year on year to year anyway' (HEP) and the reification of the network, or powerful interests, over time. Such reification, as suggested above, provides only a 'dead man's shoes' opportunity for new in their career academics to directly engage with policy networks and propose and diffuse new ideas and radical change. However, specific politicians and civil servants do not necessarily maintain long-term engagements with higher education policy networks as ministers and governments come and go and civil servants frequently move departments. Their careers are not, through Timing, always synchronised with higher education research.

These different career patterns or Timeframes between researchers, civil servants and other policymakers impact on developing relationships, and on establishing networks. Yet, while actual individuals within the policy making network change, the groups they represented were relatively stable: 'I think on the whole...I think you could regard it [the policy making network] as probably stable' (HEP). Networks are built on the development of relationships between people. Those involved in policy making are: 'not just faceless people. You can form lifelong relationships. They may move around but it doesn't matter. Your relationship's with them as an individual so you make the effort to talk to them, to help them when they phone up' (HER). They are also approachable and receptive to new ideas: 'most civil servants and most politicians I find are quite receptive to people' and that 'actually physically going to see them and saying the reason I think this research is important' (HEP). Here then, Timeframes were more similar. In order to have an influence on the policy making process, as one policy maker noted, you need to develop relationships and to 'build alliances with various organisations and find ways of expressing interests in common' (HEP). To develop and make best use of these alliances, higher education researchers need to invest in developing ties with positions of influence within these stable organisations regardless of who, at any time, occupies that position. In this sense, researchers need to have an ear to the ground to help guide research over time and to maintain relationships with positions of influence as the individuals in them change. Intermediaries, such as think-tanks, learned societies, funding bodies, mission groups and action groups, as more permanent, and sometimes more powerful, policy network members, can play a useful, structured role in negotiating connections and helping the Timings to improve synchronisation between policy making stages, evidence bases and established higher education research expertise.

Careers and relationships, their Timeframes and how they develop over time therefore present different challenges to those who occupy networks and different mechanisms and opportunities to either reify or radically change the topography of the network over time. Notably, and rather surprisingly, specific academics with career-long engagement in higher education policy networks are, unlike their peers in the network, stable members of the network. Here then, the Timeframes of academia and the policy world are similar. Nevertheless, the ongoing stability of the networks largely relies on organisations and institutions where power dynamics are apt to incrementally but not radically change over time. 


\section{The flow of time and the importance of timing in policy making}

While traditionally policy making has been described as rational, with evidence introduced as part of 'a defined, rationalised sequence of events' (Brown, 2014: 27), and with a linear relationship between research and policy making (Strassheim and Kettunen, 2014), either driving change or responding directly to policy concerns (Smith, 2010), respondents saw the policy world as anything but linear, and thus hard to predict in terms of its Temporality. Instead, the Temporality of policy making as mediated through time was complex, messy and unpredictable. As a funder commented, 'It's a minefield... one has to challenge any idea, there's a kind of a linear process in policy making... it's politically determined and it will depend on what the government in question wants to do, and that particular minister.' Similarly, a policy maker felt policy was made, 'in a messy, unstructured, hard to follow way, and I don't mean that in an insulting way, I think that is just how policy making, particularly, perhaps, in a democracy works.' One higher education researcher reflected: 'the second you're within it, you realise...it's multi-various and... inconsistent, temporary,... static, and...normally the variation within is as great as the variation between.' As another researcher commented, 'it's not a rational process, it's not a linear process ... it's a political process ... you're engaging ... in a political arena' (HER). Indeed, the higher education researchers recognised the arbitrariness of their engagement: 'It is a combination of luck ... and some foresight into where you think policies are going' (HER). This filtering and interpretation of evidence by policy makers as policy emerges is undoubtedly exacerbated by Tempo. Evidence may simply be used because it is readily available for (de)legitimising ideas at specific points in time during what is often a short policy development phase. Clearly, research and evidence used in policy making is borne from serendipity, windows of opportunity in time (Dunn and Laing, 2017) or that existing research and evidence is biding time till the right policy problem presents itself. Here then, the Duration, or extent of time available for researchers to produce research for policy was very limited.

The implications of this complexity and Duration for evidence and its impact were stark. One funder felt the fast-acting policy world would often happily 'kind of cobble together other bits of data and try and scale them up or make assumptions based on other bits of stats, and then throw out numbers which don't really mean anything.' For researchers, impact was also messy and complex, one saying 'the ideas you develop from collective bodies of knowledge don't impact in a precise way they impact in a blunt, messy, smashing, painful way.' It is not even a question of the 'right evidence' being available nor evidence that is independently and objectively generated from an academic perspective. Control of this process, and indeed the use of evidence, appears to be limited and hard to predict. The time provided for developing policy underpinned by research and evidence is a balance between availability and adaptability. The point in time, or specific stage in the Sequence of policy making, for when research and evidence is required may similarly be based on such a balance. 
Where there is no clear entry point for evidence in the policy making process, getting the timing right so it matches the right point in the Sequence of policy making is imperative. This could require foresight of what might interest policy makers: 'it's more about anticipating and seeing where things are going, and getting a whiff of the direction of travel' (HEP), where researchers should 'spend more time getting out onto the field and talking to policy makers, to understand what it is that's going ... to better understand what's going on, to be able to anticipate better' (HEP). This suggests that opportunities for research and researchers to impact on policy happen in, to some extent, particular moments, or stages in the Sequence of policy activity. There is an argument for research and researchers to be closer to the ground to be able to 'catch the moment(s)' via applied research. The risks lie in the ability of such academics to deliver objective and independent research given the Duration or extent of time required to do this. Furthermore, whether such research is either valued, wanted or useful for the specific Sequence, or time and context where policy making occurs.

Researchers were likely to have more impact on policy in the early stages of the Sequence of policy formation, and should 'seek to find ways to engage at an earlier point in the policy process' (HEP). Resonantly, one higher education researcher said, 'I feel actually some of the work I've been doing now has helped in the background stages of policy development on specific areas, and so I feel like I probably had a nice influence at that sort of stage' (HER). Such early engagement might be well received because policy makers are unsure of an area, as one researcher reflected: 'suddenly policy makers coming to me... and it's also because they haven't got a clue, as far as I can see, they don't know what to do... they're at a complete loss' (HER). Regarding influence, if not during the agenda setting or policy formulation phase, engagement needs to be before the consultation stage when most decisions have already been made:

I don't think you can apply a hard and fast rule to every consultation that's issued, but a certain percentage will be already decided, and I think you've almost got to ... make that judgement on how much of it is already decided and... what battles do you ... fight. (HEP)

This was echoed by a higher education researcher, commenting:

I have gone to stakeholder consultation events, but I think then it's at that stage where your voice as an academic or an expert is competing... and it becomes a bit lost. So I think there's kind of a ripe time to think of when an expert opinion might be able to help provide a particular steer. (HER)

Critically, this time is early in the policy development process, before the policy has been drafted, during blue skies discussions that can shape future policy. Entry at such an early stage in the policy making Sequence, however, was considered challenging for higher education researchers, notably because of the fast Tempo at 
which policy making happened. Forms of interaction and roles for academic researchers at this stage of policy development are more concerned with academics playing a boundary spanning role or, as the 'expert opinion' suggested by a policy entrepreneur looking to develop impact.

\section{Keeping up to speed in policy making}

Higher education research was considered very slow paced in Tempo, whereas higher education policy was extremely rapid. Policy making is very much focused in the present and relevant to current policy: 'policy makers want research that's relevant to what they're doing now' (HER). Yet, what is relevant can change very quickly, sometimes because of an external driver, or the wish of the minister: '[it] might be that government has picked up...there's a problem or an issue, or the minister feels particularly strongly about something, and then there's this big push from government that we need to do something' (HEP) or 'sometimes policy making in government moves quite swiftly and sometimes it's not because of any external pressures other than the minister wants to get something done, or be seen to be achieving something' (HEP). As one funder commented: 'it's so rapid in the area we work in .... there's a sense...we're always slightly on the back foot.' It is hard not to conclude that policy development is subject to whimsy and that the negotiation process within a policy network may be either the solution to such whimsy or indeed, the cause of it. Undoubtedly though, this has significant consequences for existing research resonating with the changing landscape of concerns and interests as policy develops. It also places significant pressure on attempts to fund and deliver research evidence that resonates with such shifting concerns and interests given the Duration of time required to produce such research and the differing Tempo of the research and policy worlds.

This Tempo was considered to have major implications on higher education researchers' ability to undertake research for the policy world given the Duration of time required for research. One researcher commented that for an academic institution, if requests for research came in related to a policy, 'they can't all drop everything and go away and do 50 case studies and a 2-scale survey in an 18 month period, they haven't got the capacity' (HER) and 'if you're down to do a lecture on Wednesday you can't go away for a week... it's just, it's inviable' (HER). Higher education researchers were often not sufficiently flexible to be able to align the Timing of what they did to policy makers' needs. Research, the rigorous research that policy makers value, requires significant Duration. Both researchers and policy makers recognised that: 'if the minister wants to know about something tomorrow...even if I've got a ready sample made up, I can't do it in less than 9 months... even if I've got all the resources I can chuck at it.' (HER) and 'time must also play a huge issue in terms of evidence, because if you want academic research to provide evidence for a policy... it might take an awful lot longer' (HEP). Resonantly, one policy maker said they wanted to work more with researchers, but timescales prevented them: 'we want to ... do more commissioned 
research or work with academics, [but] the timescale ... the government ... wants an answer, or with the policy cycle, by the time we've...commissioned something, it's too late' (HEP). This ultimately had implications for the types of evidence policy makers could access: 'if you have to act quickly then it might be that new evidence...can't be commissioned or gathered and...we have to act on ...existing evidence' (HEP). Evidence-based policy making may need to concede to what can be achieved pragmatically in the time available and to recognise the importance of the Duration needed for research. The idea of a hierarchy of evidence and what dominates policy making may be more about being pragmatic about the balance between levels of resonance, rigor, reliability and relevance in the context of the Duration and different Tempos of the policy and academic worlds.

The fast Tempo of the higher education policy world again affected how research was disseminated. Academic journal publishing takes time: 'writing an academic paper can take... a year, 2 years, to print, and by then I don't really think you can influence policy much because everything's moved on' (HER). This was reinforced by a policy maker: 'sometimes the policy making environment moves so fast that a piece of work that's designed to feed into the policy making process...the world has often changed by the time it appears in a learned academic journal' (HEP). This means that higher education researchers must find other ways 'to get on their [policy makers'] radar' (HER). Thus, to be noticed, research findings must reflect policy makers' Timescape to be fast in Tempo, punchy and easily digestible, as funders recognised: 'it has to be reasonably bite-sized to get attention' and 'easily translatable into material that a minister ... with a thousand and one things on their desk can easily absorb' (HEF). Researchers echoed these views, with one saying, 'policy makers ... are busy people, they don't want a 28 page report, they want a one page report.' This translation process involves

a lot more writing, you know, I don't know, blogs, for the Times Higher [Times Higher Education, UK professional magazine]... I'm doing a lot more of that sort of stuff and actually people are far more likely to come across your work in that form. (HER)

For some researchers, this meant deeper engagement with social media and influencing not only policy makers, but also public opinion:

I've been able to use social media, and to see people's reactions, and to get a blog out quickly and I think ... if you get the blog in the right place and you time it just right, you can kind of shape it to the discourse. (HER)

As one policy maker noted: 'research can shape thinking, and become part of the public thinking, the public debate about higher education, we get to a minister through that route' (HEP). The Tempo of policy making can be problematic for higher education researchers, impacting on the kinds of research evidence policy makers draw on, with a need for evidence in a Temporal modality of immediacy. This in 
turn impacts on how researchers disseminate their work in terms of producing work that is accessible through the channels that the Tempo of policy makers dictates they can access and with the required Synchronicity or Timing to have an impact at the appropriate stage in the Sequence of policy making. These elements, along with decisions regarding the Duration of time required for research ultimately impact on what, or who, they seek to influence.

\section{Concluding remarks}

The Timescapes perspective, with its more nuanced and multidimensional view of time, enabled us to compare and contrast the views of policy makers, researchers and research funders more deeply in our exploration of the nexus of research and policy. It is somewhat easy to see how the Tempo of policy making, with tight deadline calls for evidence, is at odds with the Tempo of academic life. However, anyone working in higher education is more than aware that university life is not at all slow (see e.g. Berg and Seeber, 2016; O’Neill, 2014; Vostal, 2015). Yet, when Tempo is considered alongside other facets of time: Timeframe, Temporal modalities, Temporality, Timing, Sequencing and Duration, it is easier to understand why higher education researchers have not responded to policy makers' needs (Locke, 2009) and why policy makers and researchers are deemed to live in parallel universes (Brownson et al., 2006).

The Tempo of policy making clearly favours those who are ready and responsive (Whitty, 2006). It plays to those organisations that are set up to quickly turn around projects; bite-sized projects with clear and countable findings and a solutions or 'what works' focus (Broadbent, 2017; Cain and Allan, 2017; Francis, 2011; Lingard, 2011, 2013). While some higher education researchers are able to respond to and produce these kinds of evidence within the required Duration, or time span, many are not, and would perhaps have reservations about how they perceived the reliability and validity of the 'evidence' when shaped by such restrictions. Indeed, the incentives to engage in policy-focussed research within higher education have not always been there; engagement might even be detrimental to academic credibility (Smith, 2010). The increasing emphasis on research impact, manifested in the UK through the Research Excellence Framework for example, might, however, shift understandings of the academic value of research for policy (Whitty and Wisby, 2016), thus enabling academics to prioritise their work towards policy-focussed research. Yet, even when evidence is produced that could influence policy, there is no linear policy making process into which evidence can be Sequenced (contra Strassheim and Kuttenen, 2014). Rather, there exist windows of opportunity (Dunn and Laing, 2017) in the messy Temporality and Sequencing of policy making where research and researchers can pragmatically mobilise evidence.

In order to capitalise from these windows of opportunity, should they wish to do so, it is important researchers become known within the policy making field. This can be a long-term endeavour, where credibility is gained over the Timeframe of an academic career. The focus here is not on individual outputs, but on the 
development of ideas over time and the mechanisms by which these ideas can form part of the policy making process. Increasingly, policy making happens within influential policy networks (Ball and Exley, 2010; Pearce et al., 2014); and gaining timely, or Synchronised access to those influential networks is key. Our researcher interviewees spoke of their experiences within those networks; some were unsure how they had gained entry, others recognised their influence was only going to be short lived, or Temporal. Entry into the networks, as Ball and Exley (2010) have noted, is messy and unstable. Furthermore, it relies on developing sustained relationships (Béland and Cox, 2016), new and more direct forms of communication, and the commitment of more established higher education researchers to facilitate the entry of the new generation of researchers into the policy making arena.

What this article has demonstrated is the complexity of both policy makers and researchers' worlds, and the divergent experiences of the different aspects of time encapsulated in our application of Adam's $(1998,2008)$ Timescapes. The complex, fast-paced Tempo, non-linear Temporality and politically-driven world of policy making means aligning policy maker and researcher agendas to provide policy solutions precisely when they are needed is very difficult, and if that alignment leads to formulaic, less-risky, 'policy informed evidence' (Hartley 2006: 271), then this can be deleterious to the endeavour of research (Hammersley, 2005). Arguably, in order to align their work and so researchers can have more impact on the policy world, should they wish to do so, and so that policy makers can gain the most from existing research, an understanding of these different Timescapes can greatly benefit both parties. For higher education researchers, it may be advisable to play the long game and channel their energies into the collective endeavour of developing, understanding and extending knowledge. Here is where research ideas, over a period of time, percolate and subtly (and often subconsciously) shape public (including policy makers') opinion (Weiss, 1979), feeding into public debate (Whitty, 2006). For policy makers, should they wish to do so, it is arguably going to allow them to make more of research if they take more of this long-term perspective into account as well. Only by doing this will they have a better understanding of how the evidence they seek is developed, and how it can help inform and provide validity to the policies they seek to implement.

Ultimately, we would highlight the paramount importance of the above phrase 'should they wish to do so' that we use in reference to both higher education researchers and policy makers. It is perhaps not always a disadvantage that the research and policy worlds are separate, the longer Duration perspective for researchers means they may not be able to produce the evidence required by the shorter Duration perspective and Temporality of the policy world. Nor may higher education researchers wish to engage in research that did not take account of longer, more future focused Temporal modalities. It may, for example, be the case, that such policies are required to align with a neoliberal model, particularly in their approaches to demanding quick results, and valuing survey based quantitative data to inform policy (Boehm et al., 2013), and researchers may not wish to engage with such approaches. Conversely, policy makers may not be prepared, nor 
able, to wait a long time for research results. Nevertheless, we feel it key for higher education researchers, policy makers and funders of higher education research to reflect on the way in which time impacts upon the nature of the evidence required and the evidence it is possible to produce within the different timeframes. We believe that the above data on the one hand shows us the ways in which the different worlds, or Timescapes, of higher education research and higher education policy can be bridged, but it also allows us to see the benefits for each world of having their own Timescapes.

\section{Acknowledgements}

We acknowledge the support from our critical friends: Professor William Locke and Dr Chidochangu Mpamhanga. We also thank our interviewees who were generous with their own time.

\section{Declaration of conflicting interests}

The author(s) declared no potential conflicts of interest with respect to the research, authorship, and/or publication of this article.

\section{Funding}

The author(s) disclosed receipt of the following financial support for the research, authorship, and/or publication of this article: We acknowledge the support from the Society for Research into Higher Education who funded this research.

\section{ORCID iD}

Nick Pilcher (D) https://orcid.org/0000-0002-5093-9345

\section{References}

Adam B (1995) Timewatch: The Social Analysis of Time. Cambridge, UK: Polity Press.

Adam B (1998) Timescapes of Modernity: The Environment and Invisible Hazards. London, UK: Routledge.

Adam B (2008) The Timescape Challenge: Engagement with the invisible temporal. In: Edwards R (ed) Researching Lives Through Time: Time, Generation and Life Stories. Leeds, UK: University of Leeds, pp.7-12.

Adam B and Groves C (2007) Future Matters: Action, Knowledge, Ethics. Leiden, The Netherlands: Brill.

Ball S and Exley S (2010) Making policy with 'good ideas': Policy networks and the 'intellectuals' of New Labour. Journal of Education Policy 25(2): 151-169.

Ball SJ (2016) Following policy: Networks, network ethnography and education policy mobilities. Journal of Education Policy 31(5): 549-566.

Béland D and Cox RH (2016) Ideas as coalition magnets: Coalition building, policy entrepreneurs, and power relations. Journal of European Public Policy 23(3): 428-445.

Berg M and Seeber BK (2016) The Slow Professor: Challenging the Culture of Speed in the Academy. Toronto, Canada: University of Toronto Press. 
Boehm M, Bowman D and Zinn JO (2013) Survey research and the production of evidence for social policy. Social Policy and Society 12(2): 309-318.

Broadbent J (2017) Academic evidence, policy and practice. Public Money \& Management 37(4): 233-236.

Brooy CL and Kelaher M (2017) The research-policy-deliberation nexus: A case study approach. Health Research Policy and Systems 15(1): 75.

Brown C (2013) Making Evidence Matter: A New Perspective for Evidence-Informed Policy Making in Education. London, UK: IOE Press.

Brown C (2014) Advancing policy makers' expertise in evidence-use: A new approach to enhancing the role research can have in aiding educational policy development. Journal of Educational Change 15(1): 19-36.

Brownson RC, Royer C, Ewing R, et al. (2006) Researchers and policymakers: Travelers in different universes. American Journal of Preventative Medicine 30(2): 164-172.

Cain T and Allan D (2017) The invisible impact of educational research. Oxford Review of Education 43(6): 718-732.

Cairney P (2015) How can policy theory have an impact on policymaking? The role of theory-led academic-practitioner discussions. Teaching Public Administration 33(1): 22-39.

Cairney P and Oliver K (2017) Evidence-based policymaking is not like evidence-based medicine, so how far should you go to bridge the divide between evidence and policy? Health Research Policy and Systems 15(1): 35.

Cairney P, Oliver K and Wellstead A (2016) To bridge the divide between evidence and policy: Reduce ambiguity as much as uncertainty. Public Administrative Review 76(3): 399-402.

Clegg S (2010) Time future - The dominant discourse of higher education. Time \& Society 19(3): 345-364.

Clegg S (2014) Different times. In: Gibbs P, Ylijoki O-H, Guzmán-Venezuela C, et al (eds). Universities in the Flux of Time: An Exploration of Time and Temporality in University Life, Abingdon: Routledge, pp.108-120.

Coffé H (2017). Time use among New Zealand Members of Parliament. Time \& Society 26(3): 339-361.

Deleuze G and Guattari F (1988) A Thousand Plateaus: Capitalism and Schizophrenia. London, UK: Bloomsbury Publishing.

Dunkel CS and Anthis KS (2001) The role of possible selves in identity formation: A shortterm longitudinal study. Journal of Adolescence 24(6): 765-776.

Dunn G and Laing M (2017) Policy makers perspectives on credibility, relevance and legitimacy. Environmental Science and Policy 76: 146-152.

Dussauge-Laguna MI (2012) The neglected dimension: Bringing time back into crossnational policy transfer studies. Policy Studies 33(6): 567-585.

Ferlie E, Fitzgerald L, McGivern G, et al. (2011) Public policy networks and 'wicked problems': A nascent solution. Public Administration 89: 307-324.

Flitcroft K, Gillespie J, Salkeld G, et al. (2011) Getting evidence into policy: The need for deliberative strategies? Social Science \& Medicine 72: 1039-1046.

Francis B (2011) Increasing impact? An analysis of issues raised by the impact agenda in educational research. Scottish Educational Review 43(2): 4-16.

Goetz KH and Meyer-Sahling JH (2009) Political time in the EU: Dimensions, perspectives, theories. Journal of European Public Policy 16(2): 180-201. 
Gornitzka $\AA$ (2013) The interface between research and policy - A note with potential relevance for higher education. European Journal of Higher Education 3(3): 255-264.

Hall ET (2012) Monochronic and polychronic time. In: Samovar LA, Porter RE and McDaniel ER (eds) Intercultural Communication: A Reader. Boston, MA: Wandsworth, pp.313-319.

Hammersley M (2005) The myth of research-based practice: The critical case of educational inquiry. International Journal of Social Research Methodology 8(4): 317-330.

Hampden-Turner CM and Trompenaars F (2002) A mirror-image world: Doing business in Asia. In Warner M and Joynt P (eds) Managing Across Cultures: Issues and Perspectives. London, UK: Thomson, pp.143-167.

Hartlapp M (2017) How time empowers agency: Combining the EU Commission's political powers and its administration's advantage of acting from a long-term perspective. Journal of European Integration 39(3): 303-317.

Hartley D (2006) Pulling us apart? Relativism and instrumentalism in contemporary educational research. Educational Review 58(3): 269-272.

Hopwood N (2014) The fabric of practices: Times, spaces, bodies, things. In McLean L, Stafford L and Weeks M (eds) Exploring Bodies in Time and Space. Oxfordshire, UK: Inter-Disciplinary Press, pp.137-146.

Howlett M and Goetz KH (2014) Introduction: Time, temporality and timescapes in administration and policy. International Review of Administrative Sciences 80(3): 477-492.

Koselleck R (1979) Vergangene Zukunft Zur Semantik geschichtlicher Zeiten. Frankfurt an Main, Germany: Suhrkamp.

Kovacs P (2008) Neointellectuals: Willing tools on a veritable crusade. Journal for Critical Education Policy Studies 6(1). Available at: http://www.jceps.com/archives/567 ISSN 1740-2743 (accessed 10 April 2020).

Lawrence NS, Chambers JC, Morrison SM, et al. (2017) The Evidence Information Service as a new platform for supporting evidence-based policy: A consultation of UK parliamentarians. Evidence \& Policy 13(2): 275-316.

Lawton D (2005) Education and Labour Party Ideologies: 1900-2001 and Beyond. London, UK: Routledge Falmer.

Lingard B (2011) Policy as numbers: Accounting for educational research. The Australian Researcher 38(4): 355-382.

Lingard B (2013) The impact of research on education policy in an era of evidence-based policy. Critical Studies in Education 54(2): 113-131.

Locke W (2009) Reconnecting the research-policy-practice nexus in higher education: 'evidence-Based policy' in practice in national and international contexts. Higher Education Policy 22: 119-140.

Lomas J (2000) Connecting research and policy. Canadian Journal of Policy Research 1(1): $140-144$.

MacDonald L (2013) In their own words: US think tank 'experts' and the framing of education policy debates. Journal for Critical Education Policy Studies 11(3): 1-28.

Markus H and Nurius P (1986) Possible selves. American Psychologist 41(9): 954-969.

Mazzei LA (2014) Beyond an easy sense: A diffractive analysis. Qualitative Inquiry 20(6): $742-746$.

Oliver K, Innvar S, Lorenc T, et al. (2014b) A systematic review of barriers to and facilitators of the use of evidence by policymakers. BMC Health Services Research 14: 2.

Oliver K, Lorenc T and Innvær S (2014a) New directions in evidence-based policy research: A critical analysis of the literature. Health Research Policy and Systems 12: 34. 
O'Neill M (2014) The slow university. Forum: Qualitative Social Research 15(3). DOI: 10.17169/fqs-15.3.2226.

Pearce W, Wesselink A and Colebatch H (2014) Editorial, special issue: Evidence and meaning in policy making. Evidence \& Policy 10(2): 161-165.

Raddon A (2007) Timescapes of flexibility and insecurity: Exploring the context of distance learners. Time \& Society 16(1): 61-82.

Reisch LA (2001) Time and wealth. Time \& Society 10(2-3): 367-385.

Riach K, MacDonald P and Grant-Smith D (2017). Financial timescapes: The temporal shaping of young people's financial lives. Sociology 51(4): 800-815.

Rutter J (2012) Evidence and Evaluation in Policy Making. London, UK: Institute for Government.

Sebba J (2011) Getting research into policy: The role of think tanks and other mediators. LSE The Impact Blog. Available at: http://blogs.lse.ac.uk/impactofsocialsciences/2011/ 03/07/getting-research-into-policy-the-role-of-think-tanks-and-other-mediators/ (accessed 10 April 2020).

Smith K (2010) Research, policy and funding - academic treadmills and the squeeze on intellectual spaces. The British Journal of Sociology 61(1): 176-195. DOI:10.1111/j.14684446.2009.01307.x.

Strassheim H (2016) Knowing the future: Theories of time in policy analysis. European Policy Analysis 2(1): 150-167.

Strassheim H and Kettunen P (2014) When does evidence-based policy turn into policybased evidence? Configurations, contexts and mechanisms. Evidence \& Policy 10(2): 259-277.

Sumner A, Crichton J, Theobald S, et al. (2011) What shapes research impact on policy? Understanding research uptake in sexual and reproductive health policy processes in resource poor contexts. Health Research Policy and Systems 9(1). DOI: 10.1186/14784505-9-S1-S3

Taeihagh A (2017) Network-centric policy design. Policy Sciences 50(2): 317-338.

Van de Goor I, Hämäläinen RM, Syed A, et al. (2017) Determinants of evidence use in public health policy making: Results from a study across six EU countries. Health Policy 121(3): 273-281.

Vostal F (2015) Academic life in the fast lane: The experience of time and speed in British academia. Time \& Society 24(1): 71-95.

Weible CM and Sabatie PA (eds) (2017) Theories of the Policy Process. London, UK: Hachette UK.

Weiss CH (1979) The many meanings of research utilization. Public Administration Review 39(5): 426-431.

Wesselink A, Colebatch H and Pearce W (2014) Evidence and policy: Discourses, meanings and practices. Policy Sciences 47(4): 339-344.

Whitty G (2006) Education(al) research and education policy making it conflict inevitable. British Educational Research Journal 32(2): 159-176.

Whitty G and Wisby E (2016) Research and Policy in Education: Evidence, Ideology and Impact. London, UK: UCL IOE Press.

Young TV, Wang Y and Lewis WD (2016) Explaining how political actors gain strategic positions: Predictors of centrality in state reading policy issue networks. Educational Policy 30(6): 799-819. 